\title{
CIVILIZACIÓN E CULTURA EN ROSENDO SALVADO*
}

Ramón Máiz

Universidade de Santiago de Compostela

* O autor desexa deixar constancia do seu agradecemento a Anna Haebich, Tim Rowse, Tiffany Shellam e os arquivistas de Nova Nursia (Australia Occidental), sen cuxa xenerosa axuda esta investigación non sería posible. 


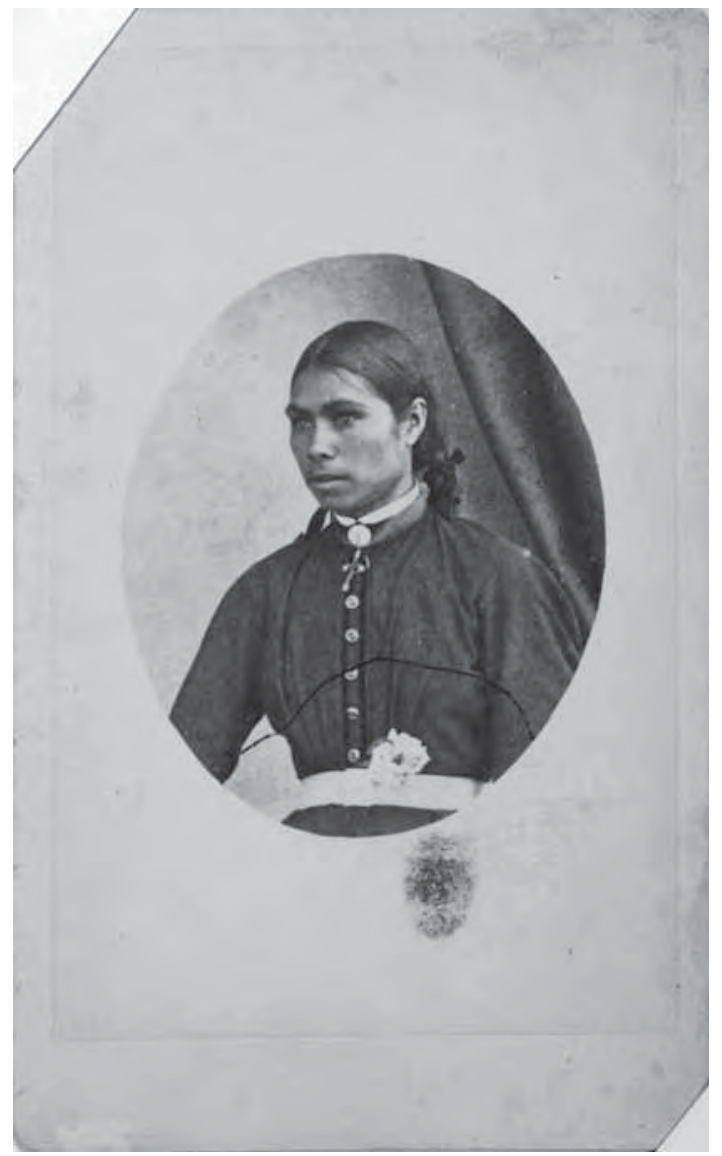


«What was there after all? Joy, fear, sorrow, devotion, valour, rage - who can tell? - but truth - truth stripped of its cloak of time». Joseph Conrad, Heart of Darkness

O obxectivo desta intervención é ensaiar unha reconstrución dos principais elementos da filosofía da civilización no pensamento de Rosendo Salvado que agroma, as máis das veces en estado práctico, no seu labor cos aborixes da Australia Occidental. Sosteremos nestas páxinas que, como fundamento teórico de Nova Nursia, se atopa unha requintada formulación que vai máis aló dun mero coñecemento práctico, improvisado e vagamente humanitario no contacto, evanxelización e aculturación dos aborixes. De feito, podemos albiscar ao abeiro do seu excepcional proxecto unha «teoría» que se separa criticamente — «in my own way»— e de xeito sistemático de todos e cada un dos máis importantes presupostos e argumentos que lexitimaron historicamente, nos séculos XIX e XX, a limpeza étnica, o xenocidio, o racismo, a colonización e, mesmo, o asimilacionismo. Unha visión, en síntese, que, espallada na súa enteira traxectoria e fragmentariamente exposta nos seus escritos, contesta e supera de xeito moi matizado o horizonte mental do mundo colonialista, sempre a contrafío dos Evangelists of Empire.

As súas propias palabras resultan ben elocuentes da autoconciencia de estar desenvolvendo, ao fío da súa experiencia, unhas ideas e principios propios, fundamento do Salvado method, a New Norcia exception que sabería recoñecer desde a metrópole Florence Nightingale (Shellam, 2012a). En efecto, escribía Salvado no seu texto «Information respecting the aboriginal natives of Western Australia», dirixido ao secretario colonial:

Podería dicirse desta hipótese que é, en rigor, máis que unha teoría, pero verdadeiramente é unha teoría [...] e esta teoría é a que regulou as miñas actuacións aquí, e aquela hipótese non é outra cousa que a posta en práctica daquela teoría co fin de acadar o noso 
caritativo, desexado e sincero obxectivo, a conversión e civilización dos aborixes da provincia. (Salvado, 1864: 6-7)

Nestas páxinas argumentaremos, en primeiro lugar, que esta teoría non naceu de vez, senón que foi o produto continxente do duro proceso dunha longa aprendizaxe, ensaios e erros, e conflitos e negociacións culturais cos aborixes yuit. $\mathrm{O}$ punto de inflexión deste proceso veu constituído polo fracaso do "grande experimento», o falecemento dos rapaces aborixes enviados a Europa para a súa educación relixiosa, do que, malia algunhas interpretacións que derivan deste episodio o fracaso do enteiro proxecto do beneditino (Ride, 2007), Salvado tirou decisivas conclusións para o seu posterior método de civilización. En segundo lugar, sosteremos que a «hipótese Salvado», mesmo desde os límites do seu horizonte civilizador e misioneiro, se distingue radicalmente doutros intentos coloniais da época, aos que de ningún xeito pode ser asimilado. Moito menos, reducido á «inxustificada deportación, quizais o primeiro exemplo de deportación infantil sistemática da historia de Australia» (Hills, 2008: 156). De feito, como veremos decontado, moitas das súas achegas serán de curso normal, século e medio máis tarde, nos paradigmas recentes do recoñecemento, o pluralismo cultural e o multiculturalismo. En terceiro lugar, amosaremos que a visión do abade reviste unha riqueza de temas, perspectivas, argumentos, prácticas e deseños institucionais de extraordinaria complexidade. Ao noso entender, será especialmente na creativa tensión conceptual, sempre aberta e non resolta, mesmo sen saída, entre civilización e cultura, onde vertebrará outras como poboación/ pobo, autonomía/autenticidade, moralidade/eticidade, universalismo/particularismo, artificio/natureza, etc., nas que resida a cerna da súa por tantos motivos senlleira achega.

Falamos de tensión non resolta porque o eixe do método de Salvado reside xustamente en esquivar dous extremos simplificadores: a tese colonialista dominante da superioridade indiscutible da civilización occidental e o desprezo conseguinte das culturas indíxenas consideradas como inferiores, non aptas para a civilización e, mesmo, destinadas á extinción (doomed race theory); a tese da inmersión acrítica no particularismo cultural, a valoración da diferenza qua diferenza e a consonte aplicación de estándares exclusivamente internos ao mundo aborixe renunciando ao exame crítico das relacións de poder, submisión e explo- 
tación presentes (tamén) nas culturas minoritarias, nas súas tradicións e institucións (opresión, xerontocracia, patriarcalismo, etc.).

Examinemos, pois, de modo por forza esquemático, algúns elementos da rede semántico-conceptual de oposicións e asociacións que constitúe a matriz intelectual sobre a que se edifica a visión innovadora de Salvado.

1.- A primeira tensión que percorre a enteira traxectoria de Salvado, tendo en conta da súa condición de misioneiro, é a de relixión/secularización. Chama poderosamente a atención, en alguén tan profundamente cristián, que dedicou toda súa vida (desde 1846 ata 1903) (Russo, 1980; Linage, 1999; Prada, 2014) ao compromiso católico máis difícil imaxinable naquela altura, á evanxelización dos nativos dos antípodas — desbotando en 1852 o tentador ofrecemento da sé episcopal de Lugo: «Prefiro as almas ás rendas. Voume para Australia»—, chama a atención, dicimos, o peculiar secularismo do seu achegamento ao labor evanxelizador e civilizador.

Por unha banda, cómpre salientar o feito da nada evidente elección da comunidade, de que o labor de Salvado se dirixise aos aborixes australianos, considerados como raza perdida para a causa da civilización e a cristiandade (Prada, 2014: 10-28), percibida polos colonizadores e as igrexas protestantes como raza degradada, inferior e condenada á extinción, e non aos brancos, como adoitaba facerse no século XIX en Australia. En efecto, nas súas propias palabras: «En Australia os europeos absorben toda a mente, todo o tempo, todos os medios dos misioneiros, e os pobres salvaxes permanecen enteiramente abandonados e esquecidos [...]. Todo, absolutamente todo, se fai a prol dos europeos; nada, absolutamente nada, a prol dos salvaxes» (Salvado, 1883: 432).

Desde a propia escolla inicial da comunidade por evanxelizar, desprezada e desbotada por todos, ata os métodos —inicialmente nómades, con posterioridade da man do establecemento da misión-, Salvado era ben consciente de que Nova Nursia constituía «unha rara excepción», sempre a contracorrente de colonos, protestantes e mesmo da súa Igrexa:

Conviene ricordarsi che né il vescovo, né il clero, né i cattolici della Diocesi di Perth contribuirono giammai con un soldo in pro della Missione de Nuova Norcia, e che per il contrario, el Santo padre Pio IX, ebbe a concedere una sanatoria al Diocesano di Perth per 10.000 libre spesi in pro degli europei invece de spenderli in pro degl'indigeni o selvaggi a cui appartenevano. (Salvado, 1883: 402) 
Agora ben, é notoria a ausencia de fundamentalismo ningún no seu proceder. A obra evanxelizadora e espiritual de Salvado, desde a fidelidade aos seus valores e principios, amosa unha insólita vertente secular, mesmo materialista, se se permite a expresión, que o leva a considerar o benestar físico, o corpo, a alimentación e a saúde dos aborixes como algo prioritario á salvación das súas almas:

$[\ldots]$ os misioneiros $[\ldots]$ deben atender asemade as súas necesidades espirituais e temporais [as dos pobos salvaxes]. De aquí que sexa preciso que unha misión fundada con tal obxecto se provexa de cantos bens materiais lle sexa posible, non tanto para se enriquecer ela mesma, senón para subministrarlle todo o necesario a cada familia salvaxe que, deixando a súa vida nómade e ociosa, queira establecerse nun lugar determinado. (Salvado, 1852: 307) ${ }^{1}$

A su dedicación á saúde dos nativos, a procura de cura para as súas enfermidades máis frecuentes, valeulle a Salvado o nome de Bolya Gumbar, «o grande doutor» (Shellam, 2012a: 114). No mesmo sentido falan a súa orixinal atención ao exercicio físico o aire libre, o traballo agrícola, a hixiene das instalacións na misión (luz, temperatura, ventilación das estancias, etc.), o respecto polas actividades nativas de recolección e caza no ermo.

Aínda máis, o benestar dos aborixes faino depender Salvado non tanto da súa pronta conversión senón das estruturas familiares, económicas e sociais no seo das cales aqueles desenvolvían a súa vida. Nesta orde de cousas, Salvado aposta, de xeito sorprendente para os seus contemporáneos, pola prioridade do traballo manual sobre o intelectual, polo coidado da saúde e a alimentación; antes que polo alimento espiritual da doutrina, polo exercicio físico ao aire libre. Incluso, resulta de grande interese comprobar como o traballo manual, "o sistema de traballo físico», debe primar, ao seu xuízo, sobre a obsesión de «SOAMENTE [remarcado así no orixinal] ensinarlles a ler e escribir» (Salvado, 1864: 7). Nada hai máis significativo para estes efectos que a febril pescuda e investigación por parte do noso beneditino das causas da mortalidade dos nativos. Lonxe de atribuír a extraordinaria taxa de falecementos, con fatalismo e pesimismo racistas,

\footnotetext{
${ }^{1}$ Rosendo Salvado (2014): Memorias históricas sobre a Australia e particularmente sobre a Misión Beneditina de Nova Nursia e os usos e costumes dos australianos, Santiago de Compostela, Xunta de Galicia / Parlamento de Galicia / Consello da Cultura Galega, 276-277. [N. da T.]
} 
ao carácter devecente e inferior da súa raza ou aos designios inescrutables de Deus, ao seu entender resulta debedora de causas ben concretas: «As enfermidades que se lles pegaron, o arsénico e as armas de fogo» (Salvado, 1852 [1946]: $351)^{2}$. A iso cómpre engadirmos a diagnose das causas da vulnerabilidade dos indíxenas, que Salvado non sitúa na súa deficitaria fisioloxía, senón nos equivocados métodos «civilizadores» dos gobernos coloniais e das igrexas.

Mesmo a minuciosa atención demográfica e estatística á «poboación» aborixe, que logo veremos, resulta debedora desta atención material aos modos de vida, alimentación, hábitos, tradicións, hábitat, así como para os efectos da limpeza étnica e xenocidio sistemáticos — de «aclarado» (clearing) racista, en palabras de Anna Haebich (Haebich, 2004) — por parte dos colonos e dos gandeiros brancos (Moses, 2004; Maddison, 2011).

2.- A segunda tensión que permite enxergar a traxectoria de Salvado, e sobre a que cómpre chamar a atención, é a de razón/sensibilidade. Fronte ás teorías en voga na época sobre o escuro porvir dos aborixes, quer as teses do darwinismo social que os declaraban non aptos para a civilización, quer o estaren deixados da man de Deus, o que facía inútiles os esforzos a prol da súa evanxelización, Salvado cultiva un coñecemento desprexuizado baseado na observación empírica dos feitos, da man do contacto e a convivencia efectiva e respectuosa cos nativos — «aborixe cos aborixes», subliñou, con grande acerto, Giulio Cipollone, quen pon o acento na aproximación igualitaria de Salvado aos aborixes, insólita no contexto racista da época, que se manifesta progresivamente no abandono da súa consideración de salvaxes e a crecente personalización e proximidade no trato, o emprego de nomes propios, as expresións de amizade: «o meu amigo e fiel compañeiro» (Cipollone, 2011: 213). Fronte aos prexuízos ideolóxicos do racismo e do colonialismo, Salvado privilexia o contacto directo, a observación polo miúdo e respectuosa, a experimentación, o ensaio de proba e erro, atento sempre ao que falen os feitos, pois na súa idea «contra a forza dos feitos ningún argumento pode sosterse», e de aí a súa rotunda conclusión: «Voler negare loro la capacitá della educazione intelletuale, sarebbe los stesso que voler negare al fuoco la propietà di riscaldare e di bruciare» (Salvado, 1883: 340). Tales son os saberes

\footnotetext{
${ }^{2}$ Da tradución: íd., 325. [N. da T.]
} 
de Salvado sobre os aborixes: coñecemento local, é dicir, situado, produto da súa cotiá observación participante, razón encarnada, a contrafío da razón universal ilustrada, e xa que logo factor decisivo para acadar a confianza daqueles.

Pero, malia a súa insaciable curiosidade — da historia natural á antropoloxía, pasando polo proceso de colonización-, que testemuñan as Memorias históricas sobre a Australia..., non todo era coñecemento no beneditino; o sentido musical de Salvado prolongábase ademais nunha extraordinaria sensibilidade humana e gran capacidade para a empatía cos Outros. Chama a atención, como sinala o seu biógrafo Russo, a súa predisposición para conseguir a proximidade, a amizade e a confianza dos aborixes (Russo, 1980: 126), calidade que — sumada ás grandes diferenzas ideolóxicas — o separaba da «cold rationality» do moi tradicionalista Serra, o seu inicial compañeiro de fatigas misioneiras (Russo, 1980: 52).

Velaí unha rara síntese de razón e sensibilidade. O rechamante, meticuloso deseño racional da estrutura da misión, na súa propia concepción diriamos urbanística, unha verdadeira cidade no ermo de Nova Nursia, non pode ocultar o coidado, a exquisita sensibilidade que amosa Salvado no trato cos aborixes, a súa admiración e aberta simpatía pola súa afouteza, intelixencia, cultura (ritos, música, danza, tatuaxes, cerimonias), o marabillado descubrimento da capacidade de viviren aqueles con dignidade nun contorno hostil. Recordemos, por exemplo, a súa aprendizaxe da lingua yuit, a demorada atención ás variedades dialectais desta, e mesmo a entusiasta valoración que fai o abade: «A linguaxe australiana non ten nada de áspera e gutural [...]. Ao contrario, está dotada de sons graves e sonoros, moi similares aos harmoniosos da nosa lingua, e flexibles e suaves coma os mellores que posúe a italiana» (Salvado, 1852: 365) . $^{3}$.

3.- A terceira tensión que queremos referir está moi vinculada á anterior, pero reviste un especial relevo nos escritos de Salvado. Referímonos á dicotomía intereses/emocións. Chama a atención que un dos principais mecanismos civilizadores que postula teoricamente, e pon en práctica, Salvado sexa o concepto de autointerese, de interese de seu; a saber: non se trata soamente de que os aborixes como base indispensable da súa autonomía e liberdade dediquen parte do seu tempo

${ }^{3}$ Da tradución: íd., 342. [N. da T.] 
ao traballo agrícola, como logo examinaremos; deben posuír, ademais, ao xuízo do abade, un abano de incentivos selectivos positivos e materiais para o desenvolvemento digno do esforzo requirido, tan alleo aos seus hábitos ancestrais. Velaí o papel do autointerese que gaba nas súas Memorias históricas sobre a Australia: «[...] un dos principais móbiles das accións humanas, quizais o maior de todos, ¡o interese! Fágase en boa hora esta proba, como debe facerse, e entón verase que os australianos non só traballan en beneficio seu, coma todos os pobos civilizados do mundo, senón que ademais posúen aquela capacidade e aquel talento que tan sen merecelo se lles nega» (Salvado, 1852: 353) ${ }^{4}$.

Anos despois, na Information... de 1864, volverá insistir neste aspecto: «O autointerese é o aceite que fai funcionar todas as máquinas; prescindide do interese e non se moverá ningunha vontade, pois nada se fai por nada» (Salvado, 1864: 7). De aí que os nativos deban percibir o xusto froito do seu traballo agrario como incentivo polo seu esforzo, aprendizaxe e mellora. $\mathrm{O}$ interese, da man desta peculiar filosofía ilustrada e utilitarista, resulta ademais considerado por Salvado como base da autonomía e liberdade dos nativos. Adianta así a reivindicación indíxena da xusta retribución do traballo, que, canda os seus dereitos como propietarios orixinarios das terras, vai ser unha demanda dos aborixes australianos durante moitos anos —equal pay- (Kirby en Maddison, 2011: x). O traballo da terra, nas parcelas da misión, proporciona tanto o incentivo económico de percibir un salario como o incentivo moral de cimentar as bases fundamentais do autorrespecto e a dignidade, fronte ao eventual complexo de inferioridade respecto dos brancos. Tamén a estabilidade social e o sentimento de pertenza igual a unha comunidade en que frades e indíxenas comparten oficios, traballos e resultados (Russo, 1980: 125). Finalmente, constituirá mesmo unha base para reclamacións sociais e políticas de dereitos sobre a terra por parte dos aborixes de Nova Nursia (Shellam, 2014).

Pero, ao propio tempo, non pode pasar desapercibida a cabal dimensión emotiva, o cultivo da empatía, a capacidade poñerse no lugar do outro, o coidado físico e mental, o agarimo que se desprende dos ímprobos esforzos que reflicten as memorias de Salvado: a estima, o afecto, a paciencia infinita. Resulta de relevo

\footnotetext{
${ }^{4}$ Da tradución: íd., 326. [N. da T.]
} 
para isto a valoración do trato aos aborixes que se desprende dos informes de Salvado, en especial o contraste coas misións protestantes. Mentres que a Nova Nursia os nativos se achegaban voluntariamente e alí ficaban con enteira liberdade, podendo saír e regresar, mesmo ser visitados polos seus familiares, habitar vivendas deseñadas para amplas unidades familiares, dispor de vacacións..., ás misións protestantes eran conducidos as máis das veces pola forza e as tentativas de fuga multiplicábanse, tras as que eran devoltos case sempre con violencia e esposados («con le manette di ferro ai polsi» [Salvado, 1883: 309]).

4.- Outra tensión que agroma unha e outra vez na obra e nas reflexións de Salvado é a que se libra entre artificialidade e naturalidade. A civilización requiría a saída do estado de natureza, isto é, o abandono do nomadismo tradicional no ermo, onde os indíxenas adoitaban ser vítimas da limpeza étnica ou do xenocidio por parte dos colonos e das autoridades brancas. Por outra parte, así e todo, o respecto pola natureza, pola constitutiva relación dos aborixes co seu medio, devén unha dimensión capital do método de Salvado. A este respecto, por unha parte, Salvado deseña o artificio civilizador de Nova Nursia; atende coidadosamente á estrutura interna e disposición espacial dos edificios da misión, na que as casas dos indíxenas respectasen a estrutura das unidades familiares espalladas e multinivel, tomando como a base a regra de san Bieito (e quizais mesmo, a título de hipótese, certa inspiración das reducións dos xesuítas en América Latina).

Cómpre salientarmos esta plural dimensión de deseño e innovación institucional no mundo segregado e autosostible da misión, omnipresente nos desvelos de Salvado: as aulas para impartir docencia, as habitacións-dormitorio para as familias, a organización da granxa, destinada aos cultivos e ao gando, a biblioteca (para a cal Salvado percorrería Europa recollendo fondos bibliográficos), a capela, etc., innovación institucional que se basea nun obxectivo sobranceiro: a cotiá convivencia de monxes e indíxenas e o compartiren uns e outros os traballos manuais.

Pero, por outra parte, unha tal deseñada e parcial segregación dos aborixes no espazo da misión non buscaba soamente servir de protección a aqueles do contacto cos colonos europeos. Salvado, tamén, como subliñou Russo, «decatouse de que mante-lo interese no seu territorio tribal era esencial para a estabilidade social. O temor de que unha desintegración demasiado repentina dos seus vellos costumes evitase que asimilasen correctamente a cultura europea, levouno a 
propor consegui-la segregación durante polo menos un período de adaptación» (Russo, 1980: 136) . $^{5}$

No que se refire á tensión que nos ocupa, artificio/natureza, podemos evidenciar esta dicotomía conxénita en Salvado en derredor dun segundo, se ben implícito, dobre eixe; a saber: terra/territorio. Vexámolo brevemente. «Terra» refírese á dimensión do terreo considerada na súa vertente de explotación, traballo e procura do sustento individual: traballo agrícola que potencia o autointerese e proporciona as bases da autopropiedade dos indíxenas, así como da propiedade e beneficio dos produtos obtidos mediante ese traballar arreo nos predios de Nova Nursia. Cada familia posuía a súa parcela, non só base elemental da súa inserción autónoma na economía produtiva, senón, máis aló desa mera dimensión económica, auténtico alicerce do autorrespecto, da autodeterminación persoal, da liberdade, do benestar, pero tamén da responsabilidade. Ao propio tempo, o terreo é algo máis que terra para ser explotada mediante o traballo: acada dimensións de territorio, é dicir, a base física natural da comunidade, a súa paisaxe, o seu nicho ecolóxico, o seu contacto coa natureza como base da cultura, relixión, prácticas, institucións, arte, modo de vida dos aborixes. De aí a luminosa idea de Salvado de compatibilizar en todo momento ambas as súas dimensións terra/territorio: o traballo agrícola na terra co mantemento das relacións comunitarias e tradicionais co territorio. Fronte aos nefastos efectos do pechamento educativo, do excesivo indoor restraint, Salvado insistiu sempre, como parte central do seu método, na saídas ao ar libre, na posibilidade dos aborixes de ter vacacións de polo menos tres semanas vagando no bush, ámbito natural onde se desenvolvía a vida comunitaria e cuxa perda supuña auténtico dano para os nativos.

Preocupado durante anos pola causa da mortalidade, aparentemente inexplicable por razóns de enfermidade física, dalgúns nativos, cando estes, por outra parte, curaban axiña de graves feridas de caza ou combate, Salvado remata por descubrir que se trata dun tipo especial de doenza espiritual: «nostalxia», morriña, na súa propia expresión inglesa: home-sickness (Salvado, 1862: 4), causada pola perda do referente do territorio comunitario; en rigor, por privación do seu medio natural.

\footnotetext{
${ }^{5}$ George Russo (2001): O señor abade do ermo: A vida e a época do bispo Salvado, Santiago de Compostela, Consello da Cultura Galega, 166. [N. da T.]
} 
Mediante este difícil equilibrio de estabilización territorial de poboacións nómades na misión e o mantemento de trazos esenciais da súa cultura, debedora do pano de fondo natural, a través do establecemento de fronteiras porosas entre a misión e o ermo circundante, entre a terra para o traballo agrícola e o territorio como substrato natural das comunidades aborixes e a súa cultura, Salvado compatibiliza non só artificio civilizador e a natureza prístina do wilderness, senón tamén as dimensións éticas capitais da autonomía e a autenticidade. A autonomía persoal dos aborixes como individuos libres e dotados de autorrespecto a partir do traballo retribuído compleméntase en todo momento no seu proxecto coa atención á autenticidade, isto é, a capacidade de remanecer fieis os aborixes á súa cultura e comunidade, que inclúe unha relación de comunicación directa coa natureza. Natureza por outra parte non arcádica, reconciliada, benevolente, senón dura e extrema, ameazante, pero auténtica «patria» dos nativos cuxa perda deviña homesickness ou mesmo Heimatlosigkeit, sentimento de perda irreparable do lar orixinario.

5.- Ciencialarte. Constitúe esta unha tensión central na visión poliédrica de Salvado. Tensión entre ciencia e arte que podemos concretar como a ricaz, simultánea presenza no beneditino de dous mundos ben afastados: a estatística $\mathrm{e}$ a música. En efecto, por unha banda resulta sorprendente, se ben coherente coa súa xa comentada atención empírica aos «feitos», a familiaridade de Salvado coa estatística social, disciplina que estaba apenas agromando naquela altura do século XIX. Para tal efecto, constitúe un episodio de enorme interese o seu intercambio de datos e correspondencia con Florence Nightingale a partir da enquisa colonial dirixida en 1860 por aquela excepcional muller, enfermeira, pioneira da hixiene e da sanidade pública, avanzada da estatística nas ciencias sociais e, por cabo, feminista (McDonald, 2010).

O proxecto de Nightingale consistiu, como é dabondo coñecido, na realización dunha enquisa (survey method) ao mundo colonial da Commonwealth sobre as condicións de saúde, mortalidade e escolarización dos rapaces indíxenas no Imperio británico. Salvado, que viña recollendo datos sobre a poboación aborixe desde a década de 1850 , recibiu un cuestionario da devandita enquisa ao que respondeu con gran precisión e, mesmo, desenvolvendo e explicando algúns aspectos do seu «método». Rowse e Shellam teñen estudado devagar estes aspectos e ás súas achegas me remito (Rowse e Shellam, 2013). Cómpre, así e todo, subliñar o feito notorio de que Nightingale considerase Nova Nursia como unha 
luminosa «excepción» que amosaba ao seu ver que, en contra do que se viña facendo ata entón, o Imperio británico podía civilizar os aborixes sen exterminalos, sempre, iso si, que mudasen radicalmente os procedementos seguidos ata o momento; nomeadamente, mediante un proceso de educación gradual e exercicio físico sistemático. A coincidencia de Nightingale con Salvado foi dobre: 1) na confianza científica na estatística social, como proba indisputable dos feitos fronte aos prexuízos racistas da ideoloxía do colonialismo (saúde, causas de mortalidade, doomed race theory, etc.), e 2) no método educativo baseado na prioridade do physical training, fronte ao pechamento en centros educativos e a formación relixiosa compulsiva e centrada na habilidade lecto-escrita. De feito, ao presentar en 1864 o seu relatorio — «Note on the aboriginal races of Australia»— na reunión anual da National Association for the Promotion of Social Sciences, Nightingale incluíu unha longa cita do informe de Salvado (Rowse e Shellam, 2013: 25).

Pero, ao propio tempo, Salvado presta unha extraordinaria atención ás artes dos aborixes: música, pinturas, adornos, tatuaxes, poesía, danzas, etc. merecen a súa atención demorada e respecto, e dedica moito do seu tempo a observar e aprender as súas diferentes manifestacións. Canto á música, disciplina que, como é ben sabido, desempeñaba un papel central na vida de Salvado, na súa condición de pianista, organista e compositor, asombra a súa capacidade de compatibilizar o cultivo da música relixiosa occidental co respectuoso coñecemento, estudo e emprego da música tradicional indíxena. Non se trata, así e todo, dun uso instrumental para fins evanxelizadores, senón de auténtico recoñecemento do valor musical dos cantos e danzas aborixes que se traduce nunha aberta admiración:

A música australiana ten a súa parte fermosa e chistosa como a fenicia, e a súa parte grave e seria como a dórica [...]. ¿ ¿antas veces me valín eu das súas cancións de baile para os animar e alentar nos traballos do campo? [...] ao me oíren cantar Maquieló, Maquielé, que é unha das súas cancións de baile máis comúns e favoritas, obrigados, coma dunha forza irresistible, non só se erguían e seguían o canto, senón que se botaban a bailar gozosos e pracenteiros [...]. (Salvado, 1852: 368) ${ }^{6}$

${ }^{6}$ Da tradución: íd., 344. [N. da T.] 
6.- Chegamos deste xeito á cerna da visión de Salvado, a decisiva tensión creativa civilización/cultura. Por unha banda, o proxecto de Salvado resulta debedor de dúas pretensións fundamentais de universalidade: a idea de civilización («civilizar os aborixes») e a idea católica da relixión («evanxelizar os aborixes»). Estas dimensións de universalismo, con todo, non desembocan no beneditino galego en presupostos etnocéntricos ou etnocráticos, como o racismo, a superioridade cultural, o desprezo ao outro, o discurso dominante na Australia da época da dying race, da incapacidade conxénita dos indíxenas para a civilización ou mesmo para a cristianización; por cabo, da súa inevitable extinción.

A razón de que a visión de Salvado discorra por outros vieiros, a contracorrente das ideas dominantes, cómpre procurala no feito de que as irrenunciables pretensións de universalidade de Salvado se atopan moi matizadas polo seu aprecio e recoñecemento da pluralidade infinita das culturas non occidentais, polo seu respecto libre de prexuízos ás achegas dos particularismos. Para el, como pode lerse nos seus escritos, cada ser humano, cada humanidade, tiña a súa propia medida, o seu específico mundo de sentido. E a civilización debe proceder mediante unha lectura dos valores universais da ciencia e da relixión sen destruír a riqueza cultural dos pobos. A propia Nightingale tiña advertido de xeito reiterado e con gran claridade sobre os perigos da «civilización» imposta da man do Imperio: «[N] osoutros e a nosa civilización parecemos causar a extinción de razas e tribos enteiras» (McDonald, 2010: 172).

Pois ben, Salvado toma en serio a cuestión capital dirixida, con grande escándalo, por Nightingale ao Imperio británico. Nas súas propias palabras: «A pregunta de Florence Nightingale — "Podemos civilizar os aborixes sen acabar con eles?”- non é unha cuestión simple, senón un problema difícil que Deus sabe cando se resolverá» (Salvado, 1864: 4). A crítica radical do racismo —isto é, a trasposición da forma cultural, intelectual e espiritual sobre a forma somáticaque desenvolve Salvado nos seus escritos, e nomeadamente nas súas Memorias históricas sobre a Australia..., non deixa lugar a dúbidas e érguese como auténtico arco de bóveda de todo o seu proxecto:

O carácter físico e moral do australiano foi pintado con cores tan falsas que os máis o consideran como o ser máis degradado da especie humana. Polo xeral, crese raquítico e mal conformado, e moi parecido aos mesmos brutos. E algúns chegan mesmo a asegurar 
que non hai a menor diferenza entre un australiano e un orangután. Ata houbo, e non un só senón moitos, quen negou que o indíxena da Australia estivese dotado dunha alma racional. (Salvado, 1852: 345$)^{7}$

Se antes insistimos en que o excepcional método de civilización de Salvado daba prioridade en equilibrio á saúde, ás condicións de hixiene, á alimentación, ao exercicio físico e ao traballo agrícola, cómpre engadir agora outra característica de non menor relevo. O seu método articulaba as achegas da educación occidental cun amplo espazo para o cultivo e desenvolvemento das prácticas culturais por parte dos aborixes (música, baile, caza, etc.). Así, o rexeitamento do prexuízo etnocéntrico constitúe unha característica sobranceira da súa visión:

Cómpre que teñamos sempre en mente que os aborixes son exóticos ou estraños á nosa civilización. Non poden soportar a nosa comida, as nosas duras xornadas de traballo quer físico, quer mental [...]. Se miramos cara a eles con ollos europeos, se os consideramos de feito europeos e tentamos educalos como tales, autoenganámosnos. O seu caso é claramente diferente ao noso e debemos levalos á nosa alta posición, non de vez, senón do mesmo xeito en que chegamos nós mesmos, de xeito progresivo. (Salvado, 1864: 5)

De xeito progresivo — by degrees—, esta é a consecuencia clave para o método Salvado do seu abandono do eurocentrismo: evitar a imposición do modelo europeo aos aborixes e apostar por un achegamento progresivo, por un proceso gradual e autocorrixido de civilización, a partir do respecto dialóxico e o recoñecemento do valor da súa cultura. Nunha das súas respostas ao cuestionario de Nightingale, Salvado insiste con énfase extrema nos destrutivos efectos do modelo clásico de civilizar: «Temos constatado que a idea de trasladar de vez os aborixes desde o seu estado salvaxe a unha civilización avanzada non serve a outro propósito que a asasinalos». Salvado parece albiscar, como moito máis tarde descubrirán Lévi-Strauss e outros antropólogos como Geertz, que as sociedades humanas non están nunca soas; que cando máis dá a impresión de que están separadas, descubrimos que forman grupos que manteñen contactos estreitos. E xunta as diferenzas debedoras do illamento danse outras, tamén importan-

\footnotetext{
${ }^{7}$ Da tradución: id., 318. [N. da T.]
} 
tes, debidas á proximidade: desexo de opoñerse, de distinguirse, de adquirir unha personalidade propia..., ata o punto de que a diversidade resulta menos debida ao illamento que ás relacións que nos unen. É de non escaso relevo para estes efectos da perspectiva dialóxica de Salvado que no proceso de evanxelización acudise a miúdo á mitoloxía indíxena, cuxa complexidade coñeceu só tras moitos esforzos co paso do tempo, para establecer pontes, similitudes e diferenzas coa relixión católica (Russo, 1980: 163).

En suma, na tensión civilización/cultura aboia unha relación continxente e por explorar entre dimensións locais, de grande espesura ética, e dimensións universais máis restrinxidas e interpretables, unha dialéctica thick and thin, no sentido de Walzer, entre, por unha banda, valores comúns para toda a humanidade e, por outra, valores e tradicións específicos da cultura yuit. E séntese, para Salvado, que 1) a dimensión universal da catolicidade non derroga o feito de cada persoa e cada pobo posuíren a súa propia medida de xuízo; 2) a identidade colectiva se constitúe como mundo compartido de dotacións de sentido e reviste gran valor para os aborixes, cuxa erosión ou perda lles produciría dano irreparable; 3) fronte á tese da superioridade da cultura occidental, Salvado postula a igual dignidade de todas as culturas e a capacidade de exame crítico das súas prácticas, institucións e tradicións; 4) o recoñecemento desempeña un papel constitutivo na identidade colectiva dos indíxenas, tanto en sentido positivo (respecto da súa dignidade diferencial) como no negativo (estereotipos racistas de inferioridade); 5) finalmente, todo o anterior se traduce en que para Salvado os aborixes se erguen, fronte aos prexuízos despectivos do colonialismo, en verdadeiros «Outros significantes», signifying others no sentido de Mead, isto é, participantes no proceso dialóxico de construción dunha versión especifica da civilización, mediada e acomodada pola cultura aborixe.

Esta tensión maior civilización/cultura, que se prolonga na de universalismo/ particularismo, amplíase nunha adicional reelaboración da urda de valores e principios morais que están en xogo, da man do dualismo moralidadeleticidade. Moralidade, isto é, de valores cristiáns, en sentido amplo, que son postulados, por parte de Salvado, desde un soporte de humanitarismo universal (igual dignidade e valor da vida humana, patrimonio común da liberdade), que se relaciona desde o respecto pero tamén desde a crítica coa eticidade, os valores comunitarios da cultura aborixe. 
En ningún lugar como na condición social das mulleres atopamos de xeito máis claro esta tensión que estamos a explorar entre civilización e cultura, entre moralidade e eticidade. Salvado, en efecto, constata ante todo a complexa situación social das mulleres yuit: se por unha parte aquelas dispuñan de relativa autonomía — ritos de seu que excluían os homes, posibilidade de acceso á posición de xamán, capacidade de dedicarse a actividades «masculinas» como a caza, etc.- - por outra parte eran obxecto sistemático de violencia de xénero desde pequenas, sufrían unha gran perda de autonomía e liberdade, e eran obxecto de intercambio de favores, marxinación social, abandono e morte. Da man da devandita tensión civilización/cultura, Salvado procurou en todo momento mudar a subordinación, explotación e opresión sistemática das mulleres aborixes inscritas en tradicións seculares: garantíndolles o mesmo nivel de educación e preparación que aos homes.

De poucas cousas estaba máis orgulloso Salvado que do proceso de educación de Ellen Cuper, que, tras o seu proceso de educación na misión, sería nomeada directora da oficina de correos e telegrafista oficial da estación de Nova Nursia. Así, escribirá entusiasmado na súa Relazione: «Nin en soños imaxinara eu ver en 1874, isto é, 28 anos despois, establecida naqueles lugares a comunicación telegráfica e o servizo de correos oficialmente a cargo e baixo a dirección dunha muller indíxena» (Salvado, 1883: 122). De non menor relevo foi o carácter non excepcional deste feito, tendo en conta que á señora Cuper a seguiron como directoras da oficina outras dúas donas indíxenas: Sarah Curningun e Carmine Guarbak (Cipollone, 2011: 208).

7.- Todo o ata aquí examinado nos conduce á última e maior tensión na teoría e prácticas do abade do ermo: poboación/pobo. Así e todo, cómpre detérmonos brevemente nunha inicial e previa tensión: individuo/comunidade. En efecto, a construción dos aborixes como individuos do novo mundo da civilización opérase, para Salvado, como vimos, mediante o traballo agrícola retribuído e o cultivo dos incentivos do autointerese que fundamentan o autorrespecto como donos do seu destino, a súa autonomía, a súa autodeterminación persoal. Agora ben, os individuos aborixes non constitúen mónadas illadas e solipsistas, centradas na exclusiva maximización do seu autointerese. Pola contra, atópanse inseridos na propia comunidade indíxena, que constitúe unha valiosa urda de prácticas, tradicións, rituais e valores culturais que dota de sentido a súa vida. 
Deste xeito, repárese en que a autonomía individual de homes e mulleres indíxenas se constrúe, para Salvado, mediante a dotación de recursos materiais e morais que cimenten a súa liberdade, o seu proxecto de vida; en definitiva, a capacidade de pór cada un para si mesmo os seus propios fins. Pero, por outra parte, como xa salientamos, a autenticidade, isto é, a fidelidade á diferenza e o respecto activo e creativo á súa cultura, fundamenta a súa dignidade comunitaria. Agroma aquí unha dobre e capital diferenza, como axiña veremos, co modelo normalizado das misións protestantes. No que se refire ao individuo, non se trata para Salvado de proporcionar recursos a un conxunto de aborixes pasivos, en espera do seu fatal destino de decadencia e desaparición. Trátase, pola contra, dun proceso de educación e formación activa que enxerga unha nova visión dos aborixes desde a liberdade, a autodeterminación persoal, baseada na capacidade de proverse do propio sustento e tamén de asumir a responsabilidade da propia vida e, xa que logo, na capacidade de futuro de participación nas decisións económicas e políticas da misión e máis aló dela. Para Salvado, no ámbito de Nova Nursia, non se facía educación para os aborixes, senón cos aborixes. Fronte á ecuación racista do nacionalismo australiano e a súa fantasía nacional branca de estado $=$ nación $=$ raza branca $=$ cidadanía . O individuo aborixe era, de feito, para o monxe beneditino, un xermolo de cidadán dotado de dereitos e de voz propia, tanto como de apoio comunitario.

Agora ben, todas as tensións anteriormente examinadas nos conducen a outra de non pequeno relevo, a saber: a que se dá entre a consideración dos aborixes como poboación e a súa alternativa concepción como pobo. En efecto, se observamos atentamente algunha das dimensións previas: comunidade, cultura, territorio, etc., podemos comprobar como, por baixo da consideración dos indíxenas como poboación, agroma e se superpón, non eliminándoa, unha vision como grupo étnico, como pobos indíxenas.

Alén da colonización, o proceso de construción da nación australiana como nación branca, protestante e de fala inglesa situaba os aborixes, desde a independencia en 1872 , como precaria minoría tanto desde o punto de vista político, social e cultural como desde o demográfico. Pois ben, resulta de especial relevo para a dicotomía pobo/poboación, por mor dos seus diferentes obxectivos, procesos e resultados para os indíxenas (Rowse, 2012). Hoxe en día este dualismo resulta dabondo coñecido e asumido, desde o punto de vista internacional, polo 
cambio que se produciu no seo da OIT desde o Convenio 107, de 1957 — On Indigenous and Tribal Populations»—, ata a ruptura xerada polo moi influente Convenio 169, de 1989 — «On Indigenous and Tribal Peoples».

Pois ben, o coñecemento estatístico das causas da mortalidade e enfermidades dos aborixes obtido por Salvado e Nightingale apunta á consideración dos indíxenas australianos como poboación específica, dotada de características diferenciadas fronte á poboación branca hexemónica. O minucioso traballo estatístico do noso beneditino recolle así durante anos datos sobre as familias dos aborixes da rexión. Agora ben, o que comeza sendo mera contabilidade de indíxenas prolóngase na elaboración de complexos elencos de familias e redes familiares, no estudo das variedades dialectais, na recorrencia nas enfermidades máis frecuentes, nas principais causas de mortalidade, nos resultados educativos dos mozos e mozas nativos, etc.

Alén dos criterios de poboación, así e todo, e por mor das tensións antes examinadas e en particular a de civilización/cultura, por riba da idea de poboación aborixe agroma en Salvado implicitamente a consideración substantiva dos yuit como pobo. Isto é: como grupo étnico cultural singular e diferenciado, considerado como un «Outro significante» co que se establece o diálogo civilizador desde unha posición de respecto, recoñecemento e participación.

Agora ben, este paso ten extraordinarias consecuencias, tendo en conta que as diferenzas entre unha e outra consideración revisten gran calado. Para o que aquí nos interesan podemos sintetizar as principais diferenzas como segue:

1) As poboacións, meros agregados de individuos singulares, poden desaparecer a consecuencia da súa integración e dilución noutra poboación maioritaria, da man da súa invisibilidade estatística colectiva, o que Haebich denominou «extermination by neglect» (Haebich, 2000: 208; 2004: 279). De xeito moi diferente, a idea de pobo apunta a unha identidade colectiva con vocación de permanencia e interlocución estable no seo do estado (Rowse, 2012: 10).

2) O tratamento como mera poboación dun grupo étnico facilita a posta en práctica de políticas que ao consideralo «inferior» ou «non apto» para a civilización adoitan enxergar veredictos de desaparición, extinción, dexeneración, etc., do que se deriva a perda de valor moral, do autorrespecto e da dignidade. O desentendemento dos poderes públicos respecto ás súas 
enfermidades, alimentación, modos de vida, dá paso a diversas medidas de limpeza étnica, etc. Os pobos, pola contra, posúen unha identidade colectiva con dereito a recoñecemento e ao seu desenvolvemento, protección, soberanía alimentaria e igual dignidade, e dereito a unha dotación de recursos que fundamenten a igualdade de oportunidades.

3) As poboacións son unidades de medida que atomizan o grupo nun conxunto de individuos illados, sen raíces, aculturizados; en rigor, invisibilizados na súa diferenza cultural, lingüística, histórica, etc. Os pobos gozan da presunción de posuíren trazos diacríticos que conforman unha identidade colectiva: historia, lingua, propia etnicidade (mitos, símbolos, cerimonias, narrativas de autointerpretación, criterio de deslinde nosoutros/eles, propio/alleo). Repárese en que a atomización individualista propia das poboacións desposúe os grupos étnicos dos cimentos da solidariedade comunitaria indispensable para a acción colectiva (asociacións e movementos sociais indixenistas).

4) As poboacións habitan un espazo eventual, continxente e provisorio, que non ten condición de territorio de seu, hábitat propio, medio histórico no que se desenvolve a comunidade, polo que poden ser desprazadas ou resituadas polos Estados ou os mercados (voting with the feet).

5) A consideración dos indíxenas exclusivamente como poboacións torna disfuncionais os dereitos de autogoberno e de autodeterminación colectiva, e o respecto ás propias institucións e tradicións xurídicas (dereito consuetudinario, pluralismo xurídico). O propio dos pobos é dispor de capacidade autorreflexiva de adaptación mediante o exercicio do autogoberno e autodeterminación democrática.

En definitiva, tratar os aborixes exclusivamente como poboación destrúe a súa entidade como pobo diferenciado dotado de 1) trazos específicos e substantivos de identidade: tradicións, historia, identidade, dereitos culturais, relixiosos e lingüísticos; 2) dereito ao título de propiedade da terra nos seus territorios ancestrais; 3) dereitos de autodeterminación e autogoberno. Isto é, o discurso da "poboación indíxena», de xeito moi semellante ao que acontece co discurso que considera as nacións interiores dos estados plurinacionais como «provincias» ou «rexións», ten unha perversa eficacia performativa: erosiona, coa súa interpelación invisibilizadora, a diferenza específica dos grupos étnicos. Para estes efectos, 
o xeógrafo social John Taylor subliñou, por exemplo, que a elaboración dos censos de poboación de Australia implicaba a imposición dun modelo cultural da maioría branca que causaba unha distorsión da realidade indíxena. A título indicativo, a idea de que o concepto de vivenda familiar agregue catro dimensións: corresidencia, comensalidade, relacións familiares e economía doméstica, que nas comunidades aborixes se atopan a miúdo disociadas (Rowse, 2012: 124).

Finalmente, da man da análise da rede semántico-conceptual de asociacións e oposicións no pensamento de Salvado, estamos en condicións de dar cumprida conta da fonda resignificación dos aborixes como pobo e cultura, de salientarmos a súa excepcional contribución non só no contexto colonial do século XIX, senón tamén de adianto dalgunhas conquistas dos pobos aborixes que haberían de agardar ata finais do século XX.

Se consideramos as etapas da historia das políticas públicas para os aborixes en Australia (McGregor, 1997; Coopes, 2010), Salvado, desde logo, comeza o seu labor a contracorrente na fase final da etapa de contacto e conflito (I), caracterizada, a mediados do século XIX, polo exterminio físico, da man dos colonizadores brancos, provistos de armas modernas, e a violencia simbólica espallada polo discurso da inferioridade, degradación e extinción da raza aborixe. Pero mesmo na seguinte etapa, chamada de protección (II), vixente os anos iniciais da misión na vida de Salvado (1846-1903), proseguiría a crenza de que a inferioridade da raza aborixe implicaría máis pronto ou máis tarde a súa desaparición (Maddison, 2011: 51). De aí que moitas das misións e, xa que logo, as reservas indíxenas australianas fosen concibidas como dotación de lugares de precaria protección mentres o proceso de extinción se producise, ao tempo que se facilitaba a apropiación das terras aborixes, consideradas res nullius, polos colonos brancos. Unha tras outra, Salvado desafiou, como temos comprobado, as características comúns da meirande parte das reservas e das misións australianas da época: 1) a marxinación dos aborixes da súa participación na economía; 2) o desprezo lingüístico e a mestura de diferentes grupos lingüísticos para romper a cohesión social e a eventual acción colectiva dos nativos; 3) aberta discriminación xurídica, xeradora dunha condición inferior; 4) erradicación da cultura, lingua (imposición do inglés) e relixións dos aborixes e cristianización forzosa.

De xeito radicalmente diferente, o método de Salvado traduciuse nun proceso autocrítico de civilización caracterizado por 1) introducir e capacitar os aborixes 
no traballo agrícola e na economía do país; 2) o cultivo da súa autodeterminación persoal; 3) o respecto e recoñecemento da cultura. En definitiva, unha visión dos aborixes como protagonistas, desde a su propia diferenza cultural en adaptación ao novo mundo, dun incipiente proceso de autonomía e autogoberno. Cómpre recordar que, mesmo na serodia etapa chamada de asimilación (III) (de 1951 en diante) (Haebich, 2008; Elder, 2009), o abandono por parte do Goberno australiano da idea da extinción dos aborixes seguiuse traducindo en políticas de socialización autoritaria e de absorción dos pobos indíxenas na cultura branca dominante («merge them into the white community»). Soamente máis tarde, nas etapas de reconciliación (IV) nos 90, o recoñecemento da Stolen Generation e, finalmente, as desculpas do primeiro ministro Kevin Rudd en 2008 mudarían substancialmente as políticas indixenistas de Australia.

O labor de Salvado, en fin, a contracorrente da maioría dos Evangelists of Empire e da súa propia Igrexa, constituíu unha experiencia excepcional de diálogo intercultural e recoñecemento dos aborixes no mundo colonial, non exenta de limitacións, conflitos e dificultades, unha tan insólita como admirable tentativa de, por dicilo coas palabras de Tiffany Shellam, «shaking hands on the fringe» (Shellam, 2009). 


\section{REFERENCIAS BIBLIOGRÁFICAS}

ATtwood, Bain (1989): The Making of the Aborigines, Sydney, Allen \& Unwin.

Brock, Peggy (1993): Outback Ghettos: A History of Aboriginal Institutionalisation and Survival, Cambridge, Cambridge University Press.

Cipollone, Giulio / Clara ORLANDI (2011): Aborigeno con gli aborigeni per l'evangelizzazione in Australia. Il testo della Relazione (1883) per Propaganga Fide del vescovo Rudesindo Salvado, Vaticano, Libreria Editrice Vaticana.

CoOpes, Rhonda (2010): Australian Aboriginal Marginalisation in Policy Making and Education, Köln, Lambert.

ELDER, Catriona (2009): Dreams and Nightmares of a White Australia, Berna, Peter Lang.

Haebich, Anna (1992): For Their Own Good, Nedlands, University of Western Australia Press.

HAEBICH, Anna (2000): Broken Circles: Fragmenting Indigenous Families 1800-2000, Fremantle, Fremantle Arts Centre Press.

Haebich, Anna (2005): «Clearing the Wheat Belt», en A. Dirk Moses, Genocide and Settler Society, New York, Berghahn Books.

Haebich, Anna (2008): Spinning the Dream: Assimilation in Australia, Fremantle, Fremantle Press.

Hills, Stephen (2008): «The Grand Experiment of the Civilisation of the Aborigines: A Missionary Endeavour in Western Australia», en Amanda Barry et al., Evangelists of Empire?: Missionaries in Colonial History, Melbourne, Melbourne University Press.

Linage Conde, Antonio (1999): Rosendo Salvado, Santiago de Compostela, Xunta de Galicia.

Maddison, Sarah (2011): Beyond White Guilt: The Real Challenge for Black-White Relations in Australia, Sydney, Allen \& Unwin.

MCDonald, Lynn (2010): Florence Nightingale at First Hand, London, Continuum.

MCGregor, Russell (1997): Imagined Destinies: Aboriginal Australians and the Doomed Race Theory, Melbourne, Melbourne University Press.

NeILl, Rosemary (2002): White Out: How Politics is Killing Black Australia, Sydney, Allen \& Unwin.

Prada, Albino (2014): Crónica desde el país de los sin alma: Rosendo Salvado en Australia, 1846-1899, A Coruña, La Voz de Galicia. (Biblioteca Gallega).

RIDE, Anouk (2007): The Grand Experiment, Sydney, Hachette Australia.

Rowse, Tim (2002): Indigenous Futures, Sydney, New South Wales University Press.

Rowse, Tim (2012): Rethinking Social Justice: From Peoples to Populations, Canberra, Aboriginal Studies Press.

Rowse, Tim / Tiffany SHellam (2013): «The Colonial Emergence of a Statistical Imaginary», Comparative Studies in Society and History, 55:4, October.

Russo, George (1980): Lord Abbot of the Wilderness. The Life and Times of Bishop Salvado, Melbourne, The Polding Press.

SALVAdO, Rosendo (1852 [1946]): Memorias históricas sobre la Australia y la misión benedictina de Nueva Nursia, Madrid, Editorial Católica.

SALVADO, Rosendo (1864): «Information respecting the aboriginal natives of Western Australia», Western Australia, State Records Office. 
SHELlam, Tiffany (2009): Shaking Hands on the Fringe, Nedlands, University of Western Australia Press.

SHELLAM, Tiffany (2012a): «"A mystery to the medical world": Florence Nightingale, Rosendo Salvado and the risk of civilization", History Australia, 9:1, 110-135.

SHELlAM, Tiffany (2012b): “"Our Natives" and "Wild Blacks": Enumeration as a statistical dimension of sovereignty in colonial Western Australia», Journal of Colonialism and Colonial History, 13:3.

SHELlam, Tiffany (2014): “"On my ground”: Indigenous farmers at New Norcia 1860s-1900s», relatorio presentado no simposio Da civilización á cultura: Rosendo Salvado e o mundo aborixe, Santiago de Compostela, Consello da Cultura Galega, 3 e 4 de abril de 2014. 